\title{
Propriedades mecânicas de tijolos fabricados com solo e água residuária de mandioca
}

\section{Mechanical properties of manufactured bricks with soil and cassava wastewater}

\author{
Narcísio Cabral de Araújo ${ }^{1}$, Alana Pereira Ramos ${ }^{2}$, Abílio José Procópio Queiroz ${ }^{3}$, Renato Correia dos Santos ${ }^{4}$, Josué da \\ Silva Buriti $i^{5}$
}

Resumo: A vantagem do processo de fabricação de tijolos com manipueira é ser ecologicamente correto, pois não consome água, nem há necessidade de ir ao forno, economizando recursos naturais e fazendo uso de um efluente altamente poluente. Assim, este trabalho objetivou analisar as propriedades mecânicas de tijolos fabricados com solo associado à manipueira como alternativa sustentável. Foram avaliados os parâmetros absorção de água e resistência à flexão. Em conformidade com os resultados, observou-se que as massas cerâmicas apresentaram valores de absorção de água da ordem de 10 a $13 \%$, valores aceitáveis para fabricação de blocos cerâmicos e valores de resistência a flexão adequados para fabricação de tijolos maciços, tanto, os corpos de prova com queima quanto os corpos de provas sem queima. Assim, conclui-se que a troca da água pela adição da manipueira na massa cerâmica não interfere nas propriedades mecânicas e esta pode ser adicionada a massa cerâmica para fabricação de tijolos ecológicos através do processo de prensagem.

Palavras-chaves: Argilas, tijolos ecológicos, mandioca, aproveitamento de resíduos.

Abstract: The advantage of the manufacturing process of brick with cassava is being environmentally friendly because it does not consume water, and there is no need to go to the oven, saving natural resources and making use of a highly polluting effluent. This work aimed to analyze the mechanical properties of bricks made from soil associated with cassava as a sustainable alternative. Parameters were evaluated water absorption and flexural strength. In accordance with the results, it was observed that the ceramic material provided water absorption values of the order of 10 to $13 \%$, acceptable values for manufacturing ceramic blocks and bending strength values suitable for manufacture of solid bricks, both proof bodies test with burns as the proof bodies of evidence without burning. It is therefore concluded that the replacement of water by the addition of cassava the ceramic mass does not interfere with the mechanical properties and that can be added to the ceramic paste for manufacturing green bricks through the pressing process.

Key words: Clay, ecological bricks, cassava, waste recovery.

\footnotetext{
*Autor para correspondência

Recebido para publicação em 29/05/2015; aprovado em 14/06/2015

${ }^{1}$ Doutorando em Engenharia Agrícola na área de irrigação e drenagem, pela Universidade Federal de Campina Grande. E-mail: narcisioaraujo@ gmail.com

${ }^{2}$ Engenheira de Materiais, Mestra e Doutoranda em Ciência e Engenharia de Materiais, Universidade Federal de Campina Grande (UFCG). E-mail:

alanapramos@yahoo.com.br

${ }^{3}$ Engenheiro Sanitarista e Ambiental, Mestre e Doutorando em Ciência e Engenharia de Materiais, Universidade Federal de Campina Grande (UFCG). E-mail:

biliojpq@hotmail.com

${ }^{4}$ Engenheira de Materiais, Mestre e Doutorando em Ciência e Engenharia de Materiais, Universidade Federal de Campina Grande (UFCG). E-mail:

renato.materiais@gmail.com

${ }^{5}$ Químico Industrial, Mestre em Ciências e Tecnologias Ambientais e Doutorandos em Ciência e Engenharia de Materiais. E-mail: josueburiti@ hotmail.com
} 


\section{INTRODUÇÃO}

A principal matéria-prima empregada na indústria de cerâmica vermelha ou estrutural são as argilas, empregadas na fabricação de blocos de vedação e estruturais, telhas, tijolos maciços, tubos e ladrilhos e na produção de tijolos.

As argilas utilizadas na indústria de cerâmica vermelha abrangem uma grande variedade de substâncias minerais de natureza argilosa. Compreendem, basicamente, sedimentos pelíticos consolidados e inconsolidados, como argilas aluvionares quaternárias, argilitos, siltitos, folhelhos e ritmitos, que queimam em cores avermelhadas, a temperaturas variáveis entre 800 e $1.250{ }^{\circ} \mathrm{C}$. Essas argilas possuem geralmente granulometria muito fina, característica que lhes conferem, com a matéria orgânica incorporada, diferente graus de plasticidade, quando adicionada de determinadas porcentagens de água, além da trabalhabilidade e resistência a verde, a seco e após o processo de queima, aspectos importantes para fabricação de uma grande variedade de produtos cerâmicos.

A fabricação de tijolos solo-cimento já é bem desenvolvida no país, entretanto atualmente busca-se tijolos que sejam ecologicamente corretos, tijolos que façam uso de menos recursos naturais e reutilize os resíduos. A utilização da manipueira para fabricação de tijolos é uma boa alternativa. Nos estados do Ceará e Paraíba os agricultores aproveitam a manipueira para a produção de tijolos ecológicos (G1, 2009; SERTÃO INFORMADO, 2005). No estado do Ceará este material vem sendo utilizado a mais de vinte anos (PONTE, 2006).

A manipueira é o resíduo líquido gerado nas indústrias de processamento da mandioca (SILVA JÚNIOR et al., 2012), de consistência leitosa, originário da prensagem da mandioca, constituída quimicamente de amido, glicose e outros açúcares, proteínas, linamarina e derivados cianogênicos, substâncias orgânicas diversas e sais minerais (ANDRÉ et al., 2012). O líquido é extraído na etapa do processamento de prensagem da massa oriunda das raízes de mandioca raladas para a produção de farinha e/ ou extração da fécula (ARAÚJO et al., 2012).

Atualmente a manipueira pode ser utilizada na agricultura como nematicida, acaricida e inseticida, fungicida e bactericida, herbicida e adubo. Quanto a outras utilizações do efluente, pode ser aplicada na produção de álcool, indústria da borracha, culinária, produção de bebidas alcoólica e fabricação de tijolo (SILVA, 2008). A grande vantagem do processo de fabricação de tijolos com manipueira é ser ecologicamente correto, pois não consome água, nem há necessidade de ir ao forno, economizando importantes recursos naturais (SILVA, 2008; CAPELLARI et al., 2010). Quanto a restrição de uso, Silva (2008) recomenda não utilizar o tijolo na construção de reservatório de água. De acordo com o exposto acima a fabricação de tijolo utilizando manipueira em substituição a água e biomassa vegetal parece ser uma alternativa sustentável para dar uma destinação ambientalmente correta ao efluente e minimizar a exploração de recursos naturais. Porém, até o presente momento nos Websites não existem referências científicas que comprovem tais relatos.

Portanto, este trabalho objetivou analisar as propriedades físico-mecânicas da introdução da manipueira na produção de tijolos.

\section{MATERIAL E MÉTODOS}

Nessa pesquisa foram estudadas argilas utilizadas industrialmente para a produção de blocos cerâmicos no Estado da Paraíba. A argila utilizada foi coletada na bacia hidrográfica do Rio Taperoá.

A manipueira foi coletada em uma casa de farinha instalada no sítio Jardim no Município de Areia, PB.

Para a realização da análise granulométrica da argila, as massas industriais foram desaglomeradas e passadas $100 \%$ em peneira ABNT $\mathrm{n}^{\circ} .200$ (abertura 0,074 mm), dispersa em água destilada com ultra-som durante 5 minutos; em seguida, foram analisadas em uma fase líquida, associadas com um processo de medida a laser, em um equipamento da marca CILAS 1064L.

No ensaio de plasticidade a amostra foi passada em peneira ABNT $\mathrm{n}^{\circ} .80$ (abertura $0,177 \mathrm{~mm}$ ), em seguida determinou-se o limite de liquidez (LL), limite de plasticidade (LP) e índice de plasticidade (IP), conforme a NBR 6459 e a NBR 7180.

Para a determinação da análise química da amostra estudada, foram separadas duas frações de $50 \mathrm{~g}$ de massa passada $100 \%$ em peneira ABNT $\mathrm{n}^{\circ} .200$ (abertura 0,074 $\mathrm{mm}$ ), usando a eflorescência de raios-X em equipamento modelo EDX 760 da SHIMADZU.

No laboratório de Caracterização de Materiais da UAEMa/CCT do Campus I da Universidade Federal de Campina Grande, foram preparados os corpos de prova com duas composições, $\mathrm{C}_{1}$ (argila-água) e $\mathrm{C}_{2}$ (argila-manipueira), ambos com 92\% de argila (Figura 1), para posterior comparação das propriedades. Os corpos de provas foram confeccionados em forma retangular, por prensagem manual, os quais foram secos a $110{ }^{\circ} \mathrm{C}$ e sinterizados nas temperaturas de 800 e $1000^{\circ} \mathrm{C}$.

Figura 1. Corpos de prova da composição $\mathrm{C} 1$ e composição C2.

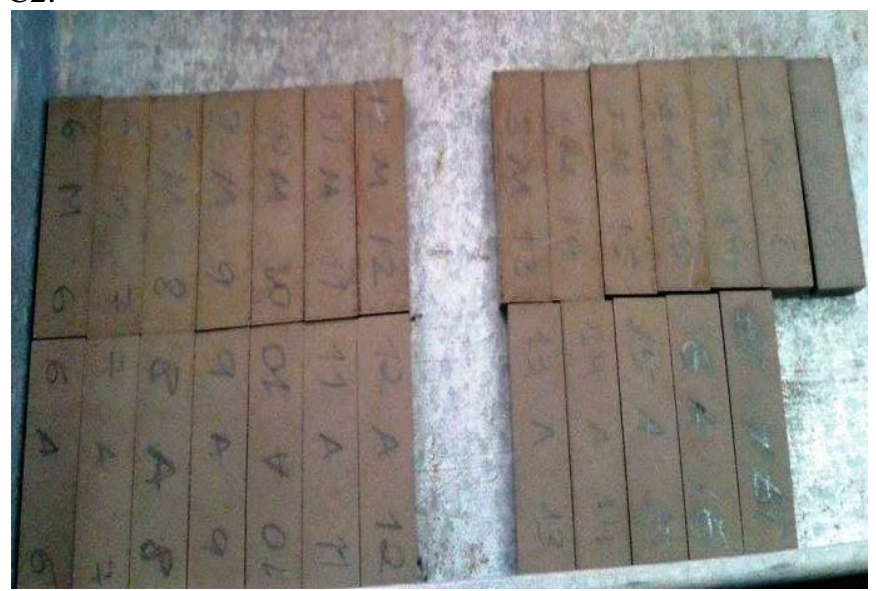

Após a queima nas temperaturas citadas, os corpos de prova foram submetidos aos ensaios referentes às propriedades físico-mecânicas, tais como: a absorção de água (AA) e a tensão de ruptura à flexão, esta pelo método de três pontos, que foram comparados com valores-limite, preconizados em laboratório para massas cerâmicas vermelhas, segundo a literatura consultada (SANTOS, 1992). Também foram realizados ensaios de ruptura à flexão, de três pontos, dos corpos de prova da composição $\mathrm{C}_{2}$ sem queima. 


\section{RESULTADOS E DISCUSSÃO}

\section{Plasticidade da argila utilizada nos ensaios}

$\mathrm{Na}$ Tabela 1 são apresentados os dados referentes ao ensaio de plasticidade da massa cerâmica por meio dos limites de Atterbeg. Onde, se observa que a amostra apresentou limite de liquidez de $38,10 \%$, limite de plasticidade de $23,55 \%$ e índice de plasticidade de $14,55 \%$. Os resultados encontram-se na faixa cujo limite de plasticidade está entre $7<$ IP $<15$ sendo considerada medianamente plástica (VIEIRA et al., 2000). De forma geral os limites de Atterberg da amostra estão dentro dos intervalos observados para cerâmica vermelha (SANTOS, 1992; MACEDO, 1997 e VIEIRA et al., 2000), sendo de 30 a $60 \%$ para o LL, 15 a $30 \%$ para o LP e 10 a $30 \%$ para o IP.

Tabela 1. Índices de plasticidade da argila.

\begin{tabular}{|c|c|c|c|}
\hline Amostra & $\mathbf{L L}$ & $\mathbf{L P}$ & IP \\
\hline & & 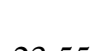 & $5-5$ \\
\hline
\end{tabular}

ATA: amostra de Taperoá

\section{Distribuição granulométrica da argila}

Na Tabela 2 é apresentada a distribuição granulométrica por tamanho de partículas da amostra ensaiada. Considerar-se a fração argila de uma matéria-prima cerâmica natural, aquela fração com granulométrica de dimensão inferior a $2 \mu \mathrm{m}$, a fração silte, entre 2 e $20 \mu \mathrm{m}$ e a fração areia com diâmetros superiores a $20 \mu \mathrm{m}$ (SILVA et al., 2010). A fração argila está relacionada, sobretudo, aos minerais argilosos, que são os responsáveis pelo desenvolvimento da plasticidade do sistema argila + água (Alves et al., 2004).

Tabela 2. Análise granulométrica da argila.

\begin{tabular}{ccc}
\hline Argila (\%) & Silte (\%) & Areia (\%) \\
\hline 9,00 & 53,49 & 37,61 \\
\hline
\end{tabular}

Comparando os resultados de plasticidade com os dados da granulometria percebe-se que o baixo índice de plasticidade provavelmente deve-se a grande quantidade da porcentagem arenosa na amostra. A amostra apresenta fração argila abaixo do mínimo indicado pelo diagrama de Winkler (PRACIDELLI; MELCHIADES, 1997; DONDO et al., 1998) para massas cerâmicas visando a produção de tijolos maciços (fração argila entre 20 e 30\%). O diagrama de Winkler auxilia no estudo da composição granulométrica ótima, indicando a dosagem de partículas finas, médias e grossas, que possibilitariam obter as melhores propriedades no produto final. No entanto, trabalhos analisando a viabilidade de utilização de argilas em cerâmica vermelha, indicaram argilas, cujas composições também não se encaixavam na região do diagrama de Winkler, como adequadas para a produção de blocos cerâmicos (SOUZA et al., 2002 e VIEIRA et al., 2003).

Na Tabela 3 é apresenta a composição química da argila utilizada na confecção dos corpos de prova. Observa-se uma composição típica de argila para cerâmica vermelha (SANTOS 1992), com predominância de $\mathrm{SiO}_{2}$ e $\mathrm{Al}_{2} \mathrm{O}_{3}$ e altos teores de $\mathrm{Fe}_{2} \mathrm{O}_{3}$.
Analisando os valores da composição química constantes na Tabela 3, observa-se que os resultados evidenciam que a amostra da massa cerâmica possui $46,90 \%$ de $\mathrm{SiO}_{2}$, provavelmente provenientes dos minerais argilosos e da sílica livre, esses resultados estão de acordo com os observados em outros trabalhos utilizando argilas para cerâmica vermelha (SILVA et al., 2010 e SANTANA et al., 2010). Os teores de alumina $\left(\mathrm{Al}_{2} \mathrm{O}_{3}\right)$ estão em torno de $22 \%$, esse baixo teor de alumínio é característico das cerâmicas vermelhas. Quando o teor de $\mathrm{Al}_{2} \mathrm{O}_{3}$ for superior a $46,0 \%$ classifica-se como argila refratária. Com relação à aplicação em produtos cerâmicos, verifica-se que o teor de ferro $(9,85 \%)$, que é o principal óxido corante das massas cerâmicas e sendo superior a 5,0\%, confere às amostras analisadas após sinterização, a coloração vermelha, cor natural dos blocos cerâmicos produzidos com as massas plásticas estudadas. Há de se destacar que não foi detectado a presença de $\mathrm{Na}_{2} \mathrm{O}$ na amostra. Com relação ao $\mathrm{MgO}$, a presença desse óxido geralmente indica a presença de dolomita ou clorita (espécie de mica) (SILVA et al., 2011).

Tabela 3. Composição Química da amostra da argila.

\begin{tabular}{cc}
\hline Óxidos & ATA \\
\hline $\mathrm{SiO}_{2}$ & 46,90 \\
$\mathrm{Al}_{2} \mathrm{O}_{3}$ & 21,55 \\
$\mathrm{Fe}_{2} \mathrm{O}_{3}$ & 9,85 \\
$\mathrm{~K}_{2} \mathrm{O}$ & 3,78 \\
$\mathrm{MgO}$ & 2,36 \\
$\mathrm{CaO}$ & 1,76 \\
$\mathrm{TiO}_{2}$ & 1,40 \\
$\mathrm{SO}_{3}$ & 0,17 \\
$\mathrm{MnO}$ & 0,08 \\
$\mathrm{ZrO}_{2}$ & 0,08 \\
$\mathrm{P}_{2} \mathrm{O}_{3}$ & - \\
$\mathrm{Outros}$ & 0,08 \\
$\mathrm{PF}$ & 12 \\
\hline
\end{tabular}

ATA: amostra de Taperoá

\section{Absorção de água dos copos de prova}

Na Tabela 4 encontram-se os resultados da absorção de água dos corpos de prova das composições $\mathrm{C}_{1}$ e $\mathrm{C}_{2}$ estudadas nas temperaturas de queima de $800{ }^{\circ} \mathrm{C}$ e $1000{ }^{\circ} \mathrm{C}$. De acordo com os dados (Tabela 4) verifica-se que as massas cerâmicas apresentam valores de absorção de água da ordem de 10 a $13 \%$, sendo inferiores ao valor máximo admissível para fabricação de blocos (SANTOS, 1992). De acordo com Silva (2011), a variação nos valores de absorção de água, pode estar relacionada ao empacotamento, ao maior percentual de sílica $\left(\mathrm{SiO}_{2}\right)$ e menor teor de fundentes. Percebe-se que há uma relação coerente entre os valores de absorção de água com o aumento da temperatura de queima.

Tabela 4. Absorção de água dos corpos de prova das composições $\mathrm{C}_{1}$ e $\mathrm{C}_{2}$.

\begin{tabular}{|c|c|c|}
\hline Temperatura & $\mathbf{C}_{1}$ & $\mathbf{C}_{2}$ \\
\hline${ }^{\circ} \mathrm{C}$ & \multicolumn{2}{|c|}{$\%$} \\
\hline 800 & $13,41 \pm 0,53$ & $13,14 \pm 0,28$ \\
\hline 1000 & $10,80 \pm 0,53$ & $10,25 \pm 0,64$ \\
\hline
\end{tabular}




\section{Ensaio de flexão}

Na Tabela 5 observa-se o comportamento das propriedades físico-mecânicas com relação às diferentes temperaturas de sinterização a 800 e $1000{ }^{\circ} \mathrm{C}$ e sem queima.

A tensão de ruptura à flexão (TRF) determina a tensão mínima que provoca a ruptura dos corpos de prova, o valor mínimo especificado é de 2,0 MPa, para blocos cerâmicos maciços, portanto, as massas cerâmicas apresentam valores adequados para fabricação de tijolos maciços, tanto as amostras após queima quanto as amostras sem queima.

Tabela 5. Resistência à flexão dos corpos de prova das composições $\mathrm{C}_{1}$ e $\mathrm{C}_{2}$.

\begin{tabular}{|c|c|c|}
\hline Temperatura & $\mathrm{C}_{1}$ & $\mathbf{C}_{2}$ \\
\hline${ }^{\circ} \mathrm{C}$ & \multicolumn{2}{|c|}{$\mathrm{MPa}$} \\
\hline 100 & $2,67 \pm 0,48$ & $3,41 \pm 0,73$ \\
\hline 800 & $6.94 \pm 1,69$ & $5,89 \pm 1,61$ \\
\hline 1000 & $8,39 \pm 0,65$ & $8,92 \pm 1,58$ \\
\hline
\end{tabular}

Determinadas as propriedades físico-mecânicas das amostras em estudo, verifica-se que todos os corpos cerâmicos analisados (com e sem queima) pelo processo de prensagem apresentaram resultados dentro da faixa de valores recomendados pela literatura, para que uma massa cerâmica possa ser utilizada na fabricação de tijolos maciços (SANTOS, 1992).

\section{CONCLUSÃO}

A troca da água pela adição da manipueira na massa cerâmica não interfere nas propriedades mecânicas e esta pode ser adicionada a massa cerâmica para fabricação de tijolos ecológicos por processo de prensagem.

\section{AGRADECIMENTOS}

Os autores agradecem ao CAPES, pela concessão da bolsa de pesquisa.

\section{REFERÊNCIAS BIBLIOGRÁFICAS}

ALVES, F. B.; VIEIRA, C. M. F.; MONTEIRO, S. N Caracterização de argilas na fazenda Santa Helena do município de Campos dos Goytacazes - RJ. In: $17^{\circ}$ Congresso Brasileiro de Engenharia e Ciência dos Materiais, Porto Alegre-RS, P. 1217 - 1231, 2004.

ANDRÉ, T. B.; SANTOS, A. C. Uso de produtos da cultura da mandioca (Manihot) na produção animal. Enciclopédia Biosfera, Centro Científico Conhecer, v.8, n.15; p.1622 1647, 2012.

ARAÚJO, N. C.; GUIMARÃES, P. L. F.; DUARTE, K. L. S.; OGATA, I. S.; LUIZ GUILHERME ABREU DE PAULA, L. G. A. Problemática dos resíduos líquidos das agroindústrias processadoras de raízes de mandioca no Estado da Paraíba. Revista Verde de Agroecologia e Desenvolvimento Sustentável, v. 7, n. 2, p 258-262, 2012.

CAPELLARI, A.; CUELLAR, C.; BRENELLI, L.; MACORIN, M.; SOUZA, P.; BIROLLI, S.;
CAMARGOS, V. O papel da química e da ciência no desenvolvimento sustentável: novos materiais, polímeros e derivados. Pontifíca Universidade Católica de Campinas, Campinas, SP, 2010. 17p. Disponível em: https://www.google.com.br/?gws_rd=ssl\#q=Resist\%C3\% AAncia+de+tijolo+de+manipueira. Acesso em 10 de dezembro de 2014.

DONDO, M.; FABBRI, B.; GUARINI, G. Spanish-Italian meeting on Clay minerals. Clay Minerals, v. 33, p. 435, 1998.

G1. Agricultores do Ceará usam tijolo ecológico. Globo Rural, 2009. Disponóvel em: http://g1.globo.com/Noticias/Brasil/0,MUL1272335$5598,00-$

AGRICULTORES+DO+CEARA+USAM+TIJOLO+ECOLOGIC O.html. Acesso em 10 de dezembro de 2014.

MACEDO, R. S. Estudo das matérias-primas e tijolos furados produzidos no Estado da Paraíba. 1997, 107p. Dissertação (Mestrado em Engenharia Química) - Universidade Federal da Paraíba UFPB, Campina Grande, PB.

PONTE, J. J. Cartilha da manipueira: uso do composto como insumo agrícola. 3.ed. Banco do Nordeste, Fortaleza CE, 2006. 66 p. Disponível em: http://pt.scribd.com/doc/102873493/Manipueira-Uso-DoComposto-Como-Insumo-Agricola\#scribd. Acesso em 23 de março de 2015.

PRACIDELLI, S. F.; MELCHIADES, F. G. Importância da composição granulométrica de massas para a cerâmica vermelha. Cerâmica Industrial, v. 02, n. 01, p. 31 - 35, 1997.

SANTANA, L. N. L.; MACEDO, R. S.; SILVA, B. J.; FONSÊCA, F. A. S.; RAMOS, O. S.; NEVES, G. A.; GONÇALVES, W. P. Métodos para determinação da plasticidade de argilas, in: $54^{\circ}$ Congresso Brasileiro de Cerâmica, Foz do Iguaçu - PR, pp. 767 - 776, 2010.

SANTOS, P. S. Ciência e Tecnologia de Argilas, $3^{\text {a }}$ Ed., vol. 1, Edgard Blücher, São Paulo, SP, 1992.

SERTÃO INFORMADO. Produtores aproveitam líquido da mandioca na fabricação de tijolos. J. Paraíba, 2005. Disponível http://sertaoinformado.com.br/conteudo.php?id=989. Acesso em 10 de dezembro de 2014.

SILVA JÚNIOR, J. J.; COELHO, E. F.; SANT'ANA, J. A. V.; SANTANA JUNIOR, E. B.; PAMPONET, A. J. M. uso da manipueira na bananeira 'terra maranhão' e seus efeitos no solo e na produtividade. Irriga, Botucatu, v. 17, n. 3, p. 353 - 363, 2012.

SILVA, A. P. Aproveitamento sustentável da manipueira. In: I Seminário Nacional Sobre Manipueira. Universidade Estadual do Sudoeste da Bahia - Vitória da Conquista, BA, 2008. Disponível em: http://webcache.googleusercontent.com/search?q=cache:i Qonw6o6X2kJ:www.emater.pi.gov.br/download/200812/ 
EMATER01_718d0905eb.docx+\&cd=1\&hl=pt-

BR\&ct=clnk\&gl=br\&client=opera. Acesso em: 23 de março de 2015.

SILVA, P. S.; RAMOS, S. O.; DANTAS, J.; NETO, J. L. B.; MACEDO, R. S. Caracterização tecnológica de argilas para produção de telhas cerâmicas na Paraíba. In: Anais do $54^{\circ}$ Congresso Brasileiro de Cerâmica, Foz do Iguaçu PR, p. $832-843,2010$.

SILVA, B. J.; GONÇALVES, W. P.; CARTAXO, J. M.; MACEDO, R. S.; MENESES, R. R.; NEVES, G. A.; SANTANA, L.N.L. Influência da taxa de aquecimento e da temperatura de queima sobre as propriedades de peças produzidas com massas da cerâmica vermelha. In: Anais do $55^{\circ}$ Congresso Brasileiro de Cerâmicas, Porto de Galinhas, PE, p. 1 - 12, 2011.
SOUZA, G. P.; SANCHEZ, R.; HOLANDA, J. N. F. Uso de rejeitos de granitos como matérias-primas cerâmicas. Cerâmica, v. 48, n.306, p. 92 - 102, 2002.

VIEIRA, C. M. F.; HOLANDA, J. N. F.; PINATTI, D. G. Caracterização de massa cerâmica vermelha utilizada na fabricação de tijolos na região de Campos dos Goytacazes - RJ. Cerâmica [online]. 2000, v. 46, n. 297, p. 14 -17. http://dx.doi.org/10.1590/S0366-69132000000100003.

VIEIRA, C. M. F.; SOARES, T. M.; MONTEIRO, S. N. Massas cerâmicas para telhas: características e comportamento de queima. Cerâmica, v. 49 n. 312, p. 245 - 250, 2003. 